\title{
Distal RTA with Hypokalemic Quadriparesis as the Initial Presentation of Primary Sjogren's Syndrome
}

\author{
Tejaswee Banavathu, MBBS, Swapnil Tripathi, MBBS*, Pankaj Sukhadiya, MBBS, Mahesh \\ Kumar Barodia, MD and Gopal Krishna Bohra, MD
}

Department of General Medicine, All India Institute of Medical Sciences, Jodhpur, Rajasthan, India

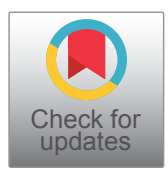

*Corresponding author: Swapnil Tripathi, MBBS, Department of General medicine, All India Institute of Medical Sciences, Jodhpur, Rajasthan, India, 342005, Tel: 8003872801

\begin{abstract}
Sjogren syndrome (SS) is a multisystemic autoimmune disorder with predominant exocrine gland involvement leading to sicca symptoms. Among extraglandular manifestations, renal involvement is commonly seen. Renal involvement can be either tubulointerstitial (TIN) or glomerular, the former being more common. Distal RTA is the most common manifestation of TIN presenting as mild hypokalaemia, metabolic acidosis and rarely with hypokalaemic periodic paralysis. We report a case of a 70-year-old female who presented with hypokalaemic periodic paralysis and metabolic acidosis diagnosed as distal RTA. On further evaluating the cause of distal RTA, the patient was diagnosed with Sjogren's syndrome and managed accordingly after assessing the ESSDAI score. Our report illustrates that Sjogren syndrome is a rare but important cause of hypokalaemic periodic paralysis.
\end{abstract}

\section{Keywords}

Primary Sjogren's syndrome, Distal renal tubular acidosis, Hypokalaemic periodic paralysis

\section{Introduction}

Renal involvement in primary Sjogren's syndrome (pSS) is not commonly defined. It is either due to tubulointerstitial involvement or less commonly due to glomerular involvement [1]. Renal tubular acidosis is seen in $9 \%$ of the patient suffering from pSS. Distal renal tubular acidosis is the most common presentation of renal involvement in a patient with pSS [2]. Clinical features of distal RTA include generalized weakness, muscle pain, polyuria, polydipsia, fractures, and renal colic. Laboratory derangement commonly includes mild hypokalaemia, metabolic acidosis, hypercalciuria, and proteinuria. Hypokalaemic periodic paralysis as the presenting symptom of pSS is uncommon. Our patient had 2 episodes of hypokalaemic periodic paralysis without renal dysfunction in the past for which she was treated with intravenous potassium and improved, but the cause was not evaluated. She presented to us with severe hypokalaemic periodic paralysis with renal dysfunction (eGFR - $26.5 \mathrm{ml} / \mathrm{min} / \mathrm{m}^{2}$ ) and metabolic acidosis. The evaluation revealed distal renal tubular acidosis (RTA) and pSS was diagnosed on basis of clinical presentation and presence of antibodies.

\section{Case Report}

A 70-year-old female with no known comorbidities presented to the Emergency Department with complaints of acute onset progressive weakness of all four limbs for 7 days, associated with decreased talk and decreased oral intake for 4 days. History of fever, headache, trauma, vomiting, or diarrhoea was absent. The patient has been admitted outside and was referred to our hospital for further management. The patient has had 2 episodes of similar complaints in the past 3 months, for which she was diagnosed to have hypokalaemia, and weakness gradually improved with correction of hypokalaemia.

At the presentation to the ED, the patient was conscious but confused, blood pressure $120 / 76 \mathrm{mmHg}$, respiratory rate $20 / \mathrm{min}$, and pulse rate of $98 / \mathrm{min}$. General physical examination revealed pallor, dry eyes, dry oral cavity with dental erosions, and bilateral upper

Citation: Banavathu T, Tripathi S, Sukhadiya P, Barodia MK, Bohra GK (2021) Distal RTA with Hypokalemic Quadriparesis as the Initial Presentation of Primary Sjogren's Syndrome. Clin Med Rev Case Rep 8:336. doi.org/10.23937/2378-3656/1410336

Accepted: January 28, 2021: Published: January 30, 2021

Copyright: (C) 2021 Banavathu T, et al. This is an open-access article distributed under the terms of the Creative Commons Attribution License, which permits unrestricted use, distribution, and reproduction in any medium, provided the original author and source are credited. 
Table 1: Lab parameters of the patient.

\begin{tabular}{|c|c|c|}
\hline Lab parameters & Patient & Reference value \\
\hline Hemoglobin & $10.9 \mathrm{gm} / \mathrm{dl}$ & $11-12 \mathrm{gm} / \mathrm{dl}$ \\
\hline WBCs & $16000 / \mu \mathrm{L}$ & $<12000 / \mu \mathrm{L}$ \\
\hline Platelets & 1.9 lacs $/ \mu \mathrm{L}$ & 1.5-4.5 lacs/ $\mu \mathrm{L}$ \\
\hline Erythrocyte sedimentation rate & $3 \mathrm{~mm}$ in $1^{\text {st }}$ hour & $<20 \mathrm{~mm}$ in $1^{\text {st }}$ hour \\
\hline HsCRP & $38.20 \mathrm{mg} / \mathrm{dL}$ & $<6 \mathrm{mg} / \mathrm{dL}$ \\
\hline Serum sodium & $141 \mathrm{mEq} / \mathrm{L}$ & 135-145 mEq/L \\
\hline Serum potassium & $1.74 \mathrm{mEq} / \mathrm{L}$ & 3.5-5.1 mEq/L \\
\hline $\begin{array}{l}\text { TSH } \\
\text { Free T3 } \\
\text { Free T4 }\end{array}$ & $\begin{array}{l}1.09 \mathrm{mlU} / \mathrm{L} \\
0.57 \mathrm{pg} / \mathrm{ml} \\
0.615 \mathrm{ng} / \mathrm{dl}\end{array}$ & $\begin{array}{l}\text { TSH - 0.3-4.0 } \mathrm{mlU} / \mathrm{L} \\
\text { Free T3 }-2.2-4.2 \mathrm{pg} / \mathrm{ml} \\
\text { Free T4 }-0.80-1.70 \mathrm{ng} / \mathrm{dl}\end{array}$ \\
\hline ABG & $\begin{array}{l}\mathrm{pH}-7.13, \\
\mathrm{pCO}_{2}-23 \mathrm{mmHg} \\
\mathrm{HCO}_{3}-6.8 \mathrm{mmol} / \mathrm{L} \\
\mathrm{Na}-140 \mathrm{mmol} / \mathrm{L} \\
\mathrm{K}-1.74 \mathrm{mmol} / \mathrm{L}, \\
\text { Chloride-122 mmol/L, } \\
\text { Serum Osmolality-305 mosm/kg }\end{array}$ & \\
\hline Urinalysis & $\begin{array}{l}\mathrm{pH}-7, \\
\text { urinary } \mathrm{Na}-68 \mathrm{mmol} / \mathrm{L}, \\
\text { urinary } \mathrm{K}-37 \mathrm{mmol} / \mathrm{l}, \\
\text { urinary Chloride-97 mmol/L, } \\
\text { urine osmolality-327 mosm/kg }\end{array}$ & \\
\hline Serum anion gap & $10.8 \mathrm{mmol} / \mathrm{L}$ & Normal range $8-12 \mathrm{mmol} / \mathrm{L}$ \\
\hline Urinary anion gap & $8 \mathrm{mmol} / \mathrm{L}$ (positive) & Positive - in favor of renal potassium loss \\
\hline TTKG & 18.45 & TTKG > 4 - suggestive of renal loss \\
\hline $\begin{array}{l}\text { Fractional bicarbonate } \\
\text { excretion }\end{array}$ & $4.10 \%$ & $<5 \%$ - in favor of distal RTA \\
\hline KFT & $\begin{array}{l}\text { Urea-83 mg/dl, } \\
\text { Creatinine-1.97 mg/dl }\end{array}$ & $\begin{array}{l}\text { Urea - } 17-43 \mathrm{mg} / \mathrm{dl} \\
\text { Creatinine } 0.6-1.1 \mathrm{mg} / \mathrm{dl}\end{array}$ \\
\hline eGFR & $26.8 \mathrm{mg} / \mathrm{min} / \mathrm{m}^{2}$ & $<60 \mathrm{mg} / \mathrm{min} / \mathrm{m}^{2}$ - renal dysfunction \\
\hline Viral markers & $\begin{array}{l}\text { HIV-negative } \\
\text { HBsAg-negative } \\
\text { Anti HCV-negative }\end{array}$ & Negative \\
\hline Autoimmune profile & $\begin{array}{l}\text { ANA-Positive, } \\
\text { Anti SS-A-positive, } \\
\text { Anti SS-B-positive, }\end{array}$ & Negative \\
\hline Schrimmers Test & $3 \mathrm{~mm}$ in both eyes & $<10 \mathrm{~mm}$ - suggestive of dry eye \\
\hline CECT brain & No abnormalities detected & \\
\hline Ultrasound abdomen & No evidence of nephrocalcinosis & \\
\hline Buccal mucosa punch biopsy & $\begin{array}{l}\text { Mild lymphocytic inflammation and } \\
\text { unremarkable minor salivary glands. }\end{array}$ & \\
\hline
\end{tabular}

mg: milligram; dL: decilitre; mmol: millimole; nmol: nanomole; L: liter; $\mu \mathrm{L}$ : microliter; U: units; $\mu$ mol: micromole; mm: millimeter; $\mu \mathrm{g}$ : microgram; gm: gram; mosm: milli osmoles

limb swelling and redness suggestive of upper limb cellulitis. Neurological examination revealed areflexic flaccid paralysis with the power of $2 / 5$ in all limbs and bilateral plantar reflex was mute. No cranial nerve deficit, autonomic disturbance, or involvement of bladder and bowel. The rest of the systemic examination was within normal limits.
After the history and clinical examination, we had differentials like Guillain-Barre syndrome, hypokalaemia, and transverse myelitis. Random blood glucose was 122 $\mathrm{mg} / \mathrm{dl}$, arterial blood gas showed $\mathrm{pH} 7.13$, bicarbonate $6.8 \mathrm{mmol} / \mathrm{L}, \mathrm{pCO}_{2} 23 \mathrm{mmHg}$, sodium $140 \mathrm{mmol} / \mathrm{L}$, potassium $1.74 \mathrm{mmol} / \mathrm{L}$ and chloride $122 \mathrm{mmol} / \mathrm{L}$. Other blood investigations are tabulated in Table 1 . So after 
getting the $A B G$ report diagnosis of normal anion gap hyperchloremic metabolic acidosis with severe hypokalaemia was made. The patient was started on IV potassium chloride supplementation and IV fluids.

Further evaluation including urinary potassium, fractional bicarbonate excretion revealed distal renal tubular acidosis. After 3 days of intravenous potassium chloride infusion patient's power and consciousness improved following which she informed regarding the history of dry mouth and grittiness in eyes for around 6 months, along with occasional joint pain. Schirmer's test showed a $3 \mathrm{~mm}$ tear flow at 5 minutes. Diagnosis of pSS was made based on Newly devised Sjogren's International Collaborative Clinical Alliance (SICCA) guidelines 4 of 6 criteria were positive along with positivity to antibodies to SSA and SSB [3]. The final diagnosis of hypokalaemic periodic paralysis with distal RTA with renal dysfunction secondary to pSS was made and found to have moderate disease activity in the renal domain according to ESSDAl scoring [4]. The patient was started on bicarbonate supplementation and oral glucocorticoids after which patient's hypokalaemia and metabolic acidosis improved.

\section{Discussion}

Sjogren's syndrome is a multisystemic autoimmune disorder commonly presenting as lacrimal and salivary gland dysfunction. Renal involvement in pSS has a prevalence of around $9 \%$, although the first clinical manifestation with renal involvement is a rare phenomenon. Renal involvement in pSS is either due to tubulointerstitial involvement or less commonly due to glomerular involvement. Lymphocytic infiltration of the renal tubules by $T$ cells, B cells, or plasma cells has been hypothesized behind the pathogenesis of renal involvement. Other causes include decreased hydrogen ion secretion secondary to the absence of a vacuolar $\mathrm{H}+$ ATPase pump in the distal tubules and antibodies to thiazide sensitive $\mathrm{NaCl}$ cotransporter (NCCT) [5]. The presence of anti-SSA, anti-SSB, and hypergammaglobulinemia are the only risk factors predisposing to renal involvement in pSS [1].

Clinical features of renal involvement include mild hypokalaemia, diabetes insipidus, renal tubular acidosis, severe hypokalaemic periodic paralysis, and Fanconi syndrome. Glomerular involvement manifested as proteinuria, haematuria and severe renal dysfunction is uncommon. Renal tubular acidosis with severe hypokalaemia causing paralysis is the most common manifestation of renal involvement in Sjogren's syndrome, although it is underdiagnosed [6].

Management of renal involvement is based on the site of kidney involvement, whether tubular or glomerular, and the ESSDAI score. Patients with mild ESSDAI scores are treated for hypokalaemia or acidosis, moderate ESSDAl is treated with oral glucocorticoids or immunosuppressant agents, and patients with severe ESSDAI are treated with glucocorticoids, rituximab, cyclophosphamide, and sometimes with plasma exchange. [2]. Our patient was treated with IV potassium supplementation along with steroids, after which she improved.

\section{Conclusion}

Hypokalemic periodic paralysis as a presenting complaint of Sjogren's syndrome is an uncommon entity. Sjogren's syndrome should be considered as a strong differential diagnosis while evaluating hypokalemic periodic paralysis associated with metabolic acidosis. Early treatment along with proper evaluation is essential to prevent recurrence of episodes of hypokalemic periodic paralysis which can be life-threatening. Our case report adds to the existing literature on renal involvement in a patient with Sjogren's syndrome.

\section{Consent}

Informed written consent was taken from the patient's son for case report writing.

\section{Conflict of Interest}

There is no conflict of interest between the authors.

\section{Financial Support and Sponsorship}

Nil.

\section{References}

1. François $H$, Mariette $X(2016)$ Renal involvement in primary Sjögren syndrome. Nat Rev Nephrol 12: 82-93.

2. Ramos-Casals M, Brito-Zerón $P$, Seror R, Bootsma H, Bowman SJ, et al. (2015) Characterization of systemic disease in primary Sjögren's syndrome: EULAR-SS Task Force recommendations for articular, cutaneous, pulmonary and renal involvements. Rheumatol Oxf Engl 54: 2230-2238.

3. Shiboski S, Shiboski C, Criswell L, Baer A, Challacombe S, et al. (2012) American College of Rheumatology classification criteria for Sjögren's syndrome: A Data-Driven, Expert Consensus approach in the SICCA Cohort. Arthritis Care Res 64: 475-487.

4. Seror R, Bowman SJ, Brito-Zeron P, Theander E, Bootsma $\mathrm{H}$, et al. (2015) EULAR Sjögren's syndrome disease activity index (ESSDAI): A user guide. RMD Open 1: e000022.

5. DeFranco PE, Haragsim L, Schmitz PG, Bastani B (1995) Absence of vacuolar $\mathrm{H}(+)$ - ATPase pump in the collecting duct of a patient with hypokalemic distal renal tubular acidosis and Sjögren's syndrome. J Am Soc Nephrol JASN 6: 295-301.

6. Jain A, Srinivas BH, Emmanuel D, Jain VK, Parameshwaran S, et al. (2018) Renal involvement in primary Sjogren's syndrome: A prospective cohort study. Rheumatol Int 38: 2251-2262. 